\title{
PELATIHAN KETERAMPILAN PENGELOLAAN LABORATORIUM BAGI GURU IPA SMP/MTs KABUPATEN LAMPUNG TIMUR
}

\author{
Oleh: \\ Amir Supriyanto ${ }^{1)}$, Sri Wahyu Suciyati ${ }^{1)}$, Runiyus Marjunus ${ }^{1)}$, dan Arif Surtono ${ }^{1)}$ \\ ${ }^{1)}$ Jurusan Fisika FMIPA Universitas Lampung \\ amir.supriyanto@fmipa.unila.ac.id, sri.wahyu@ fmipa.unila.ac.id, roniyus.1977@fmipa.unila.ac.id, \\ arif.surtono@fmipa.unila.ac.id
}

\begin{abstract}
Abstrak
Kompetensi dan keterampilan guru dalam pengelolaan laboratorium IPA SMP/MTs di Kabupaten Lampung Timur Provinsi Lampung masih rendah. Laboratorium IPA belum diberdayakan secara optimal dalam pembelajaran. Keterampilan khusus yaitu: mereparasi, memodifikasi dan menduplikasi alat-alat laboratorium yang dimiliki guru juga masih rendah. Di samping itu, kesempatan untuk mengikuti pelatihan keterampilan khusus laboratorium bagi guru IPA SMP/MTs masih minim. Tujuan kegiatan adalah untuk meningkatkan kompetensi keterampilan pengelola laboratorium IPA SMP/MTs di Kabupaten Lampung Timur. Metode kegiatan meliputi: tes awal, pemaparan materi (ceramah dan praktik yang diikuti peserta), dan tes akhir. Kegiatan dilaksanakan dua hari, yaitu tanggal 26-27 September 2019, di SMPN 1 Batanghari Kabupaten Lampung Timur. Jumlah peserta 48 orang guru, berasal dari 21 kecamatan di Kabupaten Lampung Timur. Hasil tes awal diperoleh nilai terendah 20, tertinggi 70, dan rata-rata 49. Pemberian materi dilaksanakan dengan metode ceramah, sedangkan pelatihan keterampilan peserta dibuat kelompok (satu kelompok terdiri atas 3-4 orang guru) dengan metode praktikum. Untuk mengetahui hasil pelatihan, di akhir kegiatan dilaksanakan tes. Hasil tes akhir diperoleh nilai terendah 50, tertinggi 90, dan rata-rata 69. Hal ini menunjukkan peningkatan komptensi dan keterampilan peserta yang ditunjukkan dengan peningkatan nilai tes. Materi tes berupa soal untuk mengetahui kompetensi dan keterampilan pengelolaan laboratorium.
\end{abstract}

Kata kunci: kompetensi, keterampilan khusus, laboratorium

\section{PENDAHULUAN}

Di Kabupaten Lampung Timur Provinsi Lampung terdiri atas 24 kecamatan, memiliki Sekolah Menengah Pertama (SMP) dan MTs 170 sekolah yang terdiri atas 61 sekolah negeri dan 109 swasta. Berdasarkan observasi diperoleh data bahwa belum semua sekolah memiliki laboratorium, sehingga guru dalam mengajar mengalami kesulitan untuk melaksanakan praktikum maupun demonstrasi. Pelajaran IPA di SMP merupakan pengetahuan awal bagi siswa belajar IPA di SMA/SMK, sehingga guru harus dapat menjelaskan konsep IPA yang benar dengan metode mengajar yang tepat dan menarik.

Hasil identifikasi keberadaan tenaga pengelola laboratorium IPA SMP di Kabupaten Lampung Timur menunjukkan bahwa umumnya kualifikasi pendidikan tenaga yang ditugaskan di laboratorium IPA telah memenuhi, tetapi pengetahuan dan kterampilan masih kurang. Para guru IPA yang ditugaskan sebagai pengelola laboratorium kurang memperoleh pelatihan keterampilan yang berhubungan dengan pengelolaan laboratorium. Di sisi lain, tindakan atau inovasi peningkatan kompetensi tenaga laboratorium sekolah di Kabupaten Lampung Timur masih sangat minim.

Data yang diperoleh dari interview dengan sejumlah guru IPA SMP/MTs di Kabupaten Lampung Timur, menyatakan bahwa sebagian besar guru IPA masih mengalami masalah untuk melakukan praktikum tentang topik-topik tertentu, tidak semua konsep-konsep IPA eksperimentatif dapat diajarkan dengan praktikum karena keterbatasan alat-alat dan bahan yang tersedia. 
Informasi yang diperoleh dari pengelola laboratorium IPA SMP/MTs di Kabupaten Lampung Timur, bahwa frekuensi penggunaan laboratorium IPA SMP/MTs dalam pembelajaran berpraktikum masih rendah. Salah satu kendala yang menghambat kelancaran pelaksanaan pembelajaran IPA di laboratorium adalah terbatasnya jumlah dan/atau jenis alat yang tersedia. Berdasarkan hasil observasi di beberapa laboratorium SMP/MTs diketahui keberadaan laboratorium yang "terlantarkan". Alat-alat yang ada banyak yang tidak tertangani dengan baik, tidak terawat, dan tidak dapat difungsikan secara optimal. Di samping karena sudah rusak, spek dan komponen-komponen alat yang ada tidak sesuai dengan rancangan alat praktikum pada petunjuk praktikum pegangan guru. Hal ini menunjukkan bahwa pengelolaan, pemanfaatan dan pemberdayaan laboratorium IPA di sekolah apa adanya, atau seadanya. Lagi pula tenaga yang ditugasi di laboratorium belum memiliki keterampilan/keahlian khusus untuk mereparasi, memodifikasi, dan menduplikasi alat.

Hasil observasi ini diperkuat oleh pernyataan beberapa tenaga laboratorium, kepala sekolah SMP/MTs serta Kepala Dinas Pendidikan Kabupaten Lampung Timur yang mengatakan bahwa pelatihan keterampilan khusus (reparasi, modifikasi dan duplikasi) alat bagi tenaga laboratorium (IPA khususnya) sangat diperlukan.

Berdasarkan analisis situasi tersebut, sangat diperlukan tindakan pelatihan keterampilan khusus bagi staf/tenaga laboratorium IPA SMP/MTs sehingga tenaga laboratorium dapat bekerja sesuai dengan standar kompetensi yang dipersyaratkan. Sehingga tenaga laboratorium sekolah diharapkan menjadi lebih profesional.

Tujuan kegiatan pengabdian pada masyarakat adalah untuk meningkatkan kompetensi keterampilan guru dan tenaga laboratorium IPA SMP/MTs di Kabupaten Lampung Timur. Sehingga dapat memberi solusi alternatif untuk menanggulangi kendala yang menghambat terlaksananya praktikum pembelajaran IPA di sekolah.

Rancangan pemenyelesaian masalah yang dilakukan untuk mengatasi permasalahan tersebut adalah pemberian pelatihan keterampilan khusus (reparasi, modifikasi, dan duplikasi alat) laboratorium. Di samping dalam bentuk praktek, pelatihan juga mencakup ceramah dan diskusi untuk meningkatan pemahaman tentang aspekaspek kompetensi yang harus dimilki oleh guru IPA maupun tenaga laboratorium IPA SMP.

Dimensi pengelolaan laboratorium terdiri dari: Organisasi Laboratorium; Administrasi Laboratorium (inventarisasi alat dan fasilitas laboratorium, administrasi penggunaan laboratorium, administrasi peminjaman alat-alat laboratorium, administrasi pemeliharaan alat-alat laboratorium); Keselamatan kerja di laboratorium (Sutrisno, 2010). Sehingga faktor pemeliharaan alat laboratorium berperan besar dalam mendukung kelancaran pembelajaran berpraktikum di sekolah

Peralatan laboratorium agar dapat digunakan dengan baik perlu perawatan dan perbaikan. Perawatan dan perbaikan merupakan kegiatan yang dilakukan untuk mempertahankan, meningkatkan, dan mengembalikan peralatan dalam kondisi yang baik agar siap digunakan. Perawatan alat laboratorium dimaksudkan sebagai usaha preventif atau pencegahan agar peralatan tidak rusak atau tetap terjaga dalam kondisi baik dan siap digunakan. Perbaikan alat laboratorium dimaksudkan sebagai upaya untuk mengatur/menyetel atau memperbaiki kembali peralatan laboratorium yang sudah rusak atau kurang berfungsi atau kurang layak sehingga siap digunakan untuk kegiatan praktik (Kemendikbud, 2017)

Untuk mengatasi permasalahan yang dihadapi oleh guru IPA dalam proses pembelajaran berpraktikum perlu diadakan pelatihan. Menurut Subiama (2012), pelatihan keterampilan guru IPA dapat meningkatkan kompetensi yang dimiliki dan meningkatkan pengetahuan dan keterampilan dasar laboratorium sehingga kinerjanya menjadi lebih baik.

Pelatihan juga dapat meningkatkan pengetahuan guru tentang cara memperbaiki alat ukur IPA di laboratorium, khususnya alat ukur listrik, di samping itu juga dapat meningkatkan motivasi, bakat dan minat serta kemampuan guru dalam memperbaiki alat ukur fisika (Ahmad Yani dkk., 2019).

Di samping itu, menurut Ismawati dan Trisnowati (2019), hasil capaian yang diharapkan 
dari pelatihan adalah untuk meningkatkan pengetahuan peserta: a) memahami struktur organisasi dan tugas tenaga laboratorium, b) mampu menyusun, melaksanakan, mengevaluasi program kerja laboratorium; c) dapat menerapkan kesehatan keselamatan kerja di laboratorium; d) dapat melakukan perawatan serta pemeliharaan alat dan bahan.

Menurut Yuliana dkk (2017), pembelajaran dengan pemanfaatan laboratorium IPA sangat efektif terhadap peningkatan motivasi belajar siswa, hal ini ditunjukkan dengan peningkatan nilai hasil belajar siswa.

Tuntutan dalam pembelajaran IPA tersebut tidak akan terpenuhi jika tidak ditunjang dengan pengalaman nyata kepada peserta didik, salah satunya dengan praktikum. Praktikum terlaksana dengan efektif jika dalam melaksanakan kegiatan berpraktikum di laboratorium didukung oleh kemampuan guru yang kompeten (Hofstein dan Naaman, 2007). Laboratorium merupakan tempat bagi peserta didik untuk optimalisasi keterampilan proses dan pengembangan sikap ilmiah. Aktivitas di dalam laboratorium IPA dapat meningkatkan ketertarikan peserta didik terhadap materi IPA dan berpotensi sebagai media dan alat pembelajaran yang menyumbangkan peningkatan hasil belajar peserta didik dalam pembelajaran sains (Habibi, 2012). Jika di dalam pembelajaran IPA, siswa diberikan kesempatan menggunakan sebagian ataupun seluruh inderanya secara tepat melalui aktivitas lab, maka siswa akan lebih mudah untuk memahami ilmu dan pengetahuan IPA.

Metode yang ditawarkan untuk menyelesaikan tantangan, persoalan atau kebutuhan pokok yang menjadi target kegiatan atau kesepakatan bersama adalah untuk peningkatan pengetahuan dan keterampilan modifikasi praktikum skala kecil atau KIT, yang dengan penuntun praktikumnya. Praktek/workshop modifikasi alat-alat praktikum skala kecil memanfaatkan bahan pengganti yang ramah lingkungan, biasa disebut modifikasi. Modifikasi dapat dilakukan oleh setiap guru IPA SMP/MTs. Modifikasi juga merupakan kegiatan yang direncanakan adalah pemberdayaan pengetahuan dan keterampilan guru pengelola laboratorium dalam hal pengembangan KIT praktikum skala kecil (Rizka Rida Utami, dkk. 2017)

\section{METODE}

Metode kegiatan meliputi tiga bagian. (1) awal (pretes), untuk mengetahui pengetahuan peserta tantang fungsi dan perawatan alat praktikum IPA serta keterampilan memodifikasi alat praktikum IPA. (2) Metode pelaksanaan kegiatan yang digunakan dalam bentuk ceramah-diskusi dan praktek (learning by doing). Gabungan metode ini dapat meningkatkan kemampuan pemahaman dan keterampilan peserta pelatihan yang berkaitan dengan keterampilan modifikasi alat praktikum IPA (Subamia, 2012). Ceramah dan diskusi tentang fungsi, penggunaan, pemeliharaan sarana, prasarana, peralatan, dan pemilihan bahan praktikum IPA. (3) Evaluasi atau penilaian kegiatan dilakukan terhadap proses pelaksanaan dan hasil kegiatan. Penilaian proses berhubungan dengan kehadiran peserta pelatihan dan aktifitas peserta saat mengikuti kegiatan. Akhir evaluasi proses dilakukan tes akhir. Penilaian produk dilakukan pada hasil karya praktik, yaitu berupa modifikasi peralatan praktikum IPA yang telah ditentukan.

Evaluasi serta hasil kegiatan berupa pelaporan terhadap pelaksanaan kegiatan yang telah diselesaikan pada 29 Oktober 2019, sedangkan monitoring pelaksanaan pengabdian berlangsung pada Minggu ke-2 Nopember 2019.

\section{HASIL DAN PEMBAHASAN}

\section{A. Analsis Hasil Kegiatan}

Pelaksanaan kegiatan dilaksanakan tanggal 2627 September 2019, diikuti oleh 48 guru IPA SMP yang berasal dari 21 kecamatan di Kabupaten Lampung Timur. Kegiatan diawali dengan pembukaan yang dibuka oleh Ketua MGMP IPA SMPN Lampung Timur. Selanjutnya dimulai dengan tes awal, pemaparan materi oleh penyaji (dosen), dan akhiri dengan tes akhir.

Hasil tes awal dikatehui bahwa pengetahuan peserta dalam bidang IPA masih rendah, dengan nilai terendah 20, tertinggi 70 , dan rata-rata 45 . Setelah dilakukan tes awal, dilaksanakan penyajian

$$
\text { Pendidikan }
$$


materi teori dan praktik. Saat penyajian, seluruh peserta mengikuti dengan tertib dan dengan aktif beberapa peserta mengajukan pertanyaan yang berkaitan dengan materi yang disajikan.

Pelatihan dilaksanakan selama dua hari yang terdiri atas dua bagian, yaitu teori dan praktik. Pemberian materi secara teori diberikan di hari pertama, meliputi: (1) Pemeliharaan sarana, prasarana, peralatan, dan bahan praktikum di laboratorium; (2) Fungsi, Penggunaan, dan Pemeliharaan Alat Ukur Listrik Magnet. Praktik dilaksanakan di hari pertama dan kedua, dengan dibuat kelompok. Satu kelompok terdiri atas 3-4 orang guru. Materi prektik meliputi: (1) Modifikasi Alat Praktik IPA ( ; (2) Duplikasi Pengadaan Alat Praktik IPA (alat fermentasi dan spirometer); (3) Reparasi dan perawatan Alat Praktik IPA (mikroskup, alat praktikum dari gelas, dan alat ukur listrik).

Setelah selesai penyajian materi, di akhir kegiatan diadakan tes akhir. Tes dilakukan untuk mengetahui pengaruh perubahan kompetensi dan keterampilan guru setelah mengikuti pelatihan. Materi tes berupa soal untuk mengetahui peningkatan kompetensi dan keterampilan pengelolaan laboratorium.

Hasil tes akhir diperoleh nilai terendah 50, tertinggi 90, dan rata-rata 69 . Untuk membandingkan nilai tes awal, tes akhir, dan peningkatannya disajikan pada Tabel 1, gambar 1, dan gambar 2 . Berasarkan Tabel 1 tampak bahwa terdapat peningkatan nilai tes akhir dibandingkan tes awal., dengan nilai terendah meningkat $150 \%$, nilai tertinggi meningkat $29 \%$, dan rata-rata meningkat $54 \%$. Peningkatan nilai tes akhir menunjukkan adanya peningkatan pengetahuan (kompetensi) dan keterampilan pengelolaan laboratorium bagi peserta pelatihan. Untuk menunjukkan peserta pelatihan disajikan pada gambar 3 .
Tabel 1. Hasil tes awal dan tes akhir peserta pelatihan

\begin{tabular}{|c|c|c|c|c|}
\hline No & Nama & $\begin{array}{l}\text { Pre- } \\
\text { test }\end{array}$ & $\begin{array}{c}\text { Pos- } \\
\text { test }\end{array}$ & $\begin{array}{l}\text { Pening- } \\
\text { katan (\%) }\end{array}$ \\
\hline 1 & Retno Utami & 60 & 80 & 33 \\
\hline 2 & Siti Rohela & 50 & 70 & 40 \\
\hline 3 & Hendro Yatmoko & 50 & 70 & 40 \\
\hline 4 & Ahmad Zaini & 20 & 50 & 150 \\
\hline 5 & Riwayati & 20 & 50 & 150 \\
\hline 6 & Sarwono & 40 & 70 & 75 \\
\hline 7 & Emilia Kardiyanti & 30 & 60 & 100 \\
\hline 8 & Siti Rupiah & 30 & 50 & 67 \\
\hline 9 & Joko Mursito & 60 & 80 & 33 \\
\hline 10 & Suwardi & 40 & 60 & 50 \\
\hline 11 & Okti Nurhisayati & 40 & 60 & 50 \\
\hline 12 & Sarjono & 60 & 90 & 50 \\
\hline 13 & Yesi Yosinta & 50 & 70 & 40 \\
\hline 14 & Aris R. Kurniawan & 50 & 80 & 60 \\
\hline 15 & Pangestuti Rahayu & 30 & 60 & 100 \\
\hline 16 & Tri Epriningsih & 50 & 80 & 60 \\
\hline 17 & Untung Susanto & 60 & 80 & 33 \\
\hline 18 & Sulistiyani & 40 & 60 & 50 \\
\hline 19 & Candra Arityastuti W & 50 & 80 & 60 \\
\hline 20 & Sri Utami & 40 & 60 & 50 \\
\hline 21 & Ambar Hidayati & 40 & 70 & 75 \\
\hline 22 & Eko Santoso & 60 & 90 & 50 \\
\hline 23 & Rohani Sirait & 30 & 50 & 67 \\
\hline 24 & Budi Ripwantoro & 20 & 50 & 150 \\
\hline 25 & Henny Mariana & 30 & 60 & 100 \\
\hline 26 & Cahyo Agus Setiawan & 40 & 60 & 50 \\
\hline 27 & Rudiyantoko & 70 & 90 & 29 \\
\hline 28 & Sumirah & 50 & 70 & 40 \\
\hline 29 & Sarmin & 30 & 60 & 100 \\
\hline 30 & Wahana & 30 & 60 & 100 \\
\hline 31 & I Wayan Narsoodhi & 30 & 60 & 100 \\
\hline 32 & Sulanjari & 60 & 90 & 50 \\
\hline 33 & Siti Bariroh & 40 & 60 & 50 \\
\hline 34 & Jumiati & 50 & 70 & 40 \\
\hline 35 & Dinang Pujianto & 50 & 70 & 40 \\
\hline 36 & Suharti Ningsih & 30 & 50 & 67 \\
\hline 37 & Tuti Eka wahyuni & 40 & 70 & 75 \\
\hline 38 & Salbiyah & 60 & 80 & 33 \\
\hline 39 & Nursariah & 30 & 60 & 100 \\
\hline 40 & Wiwik Sudarmiyati & 40 & 60 & 50 \\
\hline 41 & Eni Midiantari & 70 & 90 & 29 \\
\hline 42 & Kusnandar & 50 & 70 & 40 \\
\hline 43 & Ulfa Rahmi & 70 & 90 & 29 \\
\hline 44 & Rasuna Fitriati & 50 & 70 & 40 \\
\hline 45 & Jumadiono & 50 & 80 & 60 \\
\hline 46 & Eva Septiana & 50 & 70 & 40 \\
\hline 47 & Anita Kurnia Sari & 60 & 80 & 33 \\
\hline 48 & Siti Havivah & 50 & 70 & 40 \\
\hline
\end{tabular}




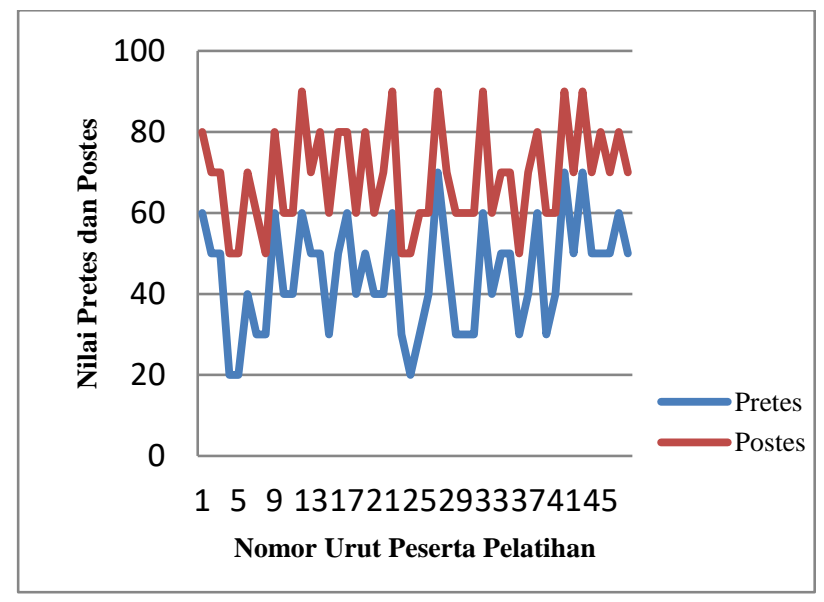

Gambar 1. Grafik nilai tes yang menunjukkan peningkatan pengetahuan setiap peserta pelatihan

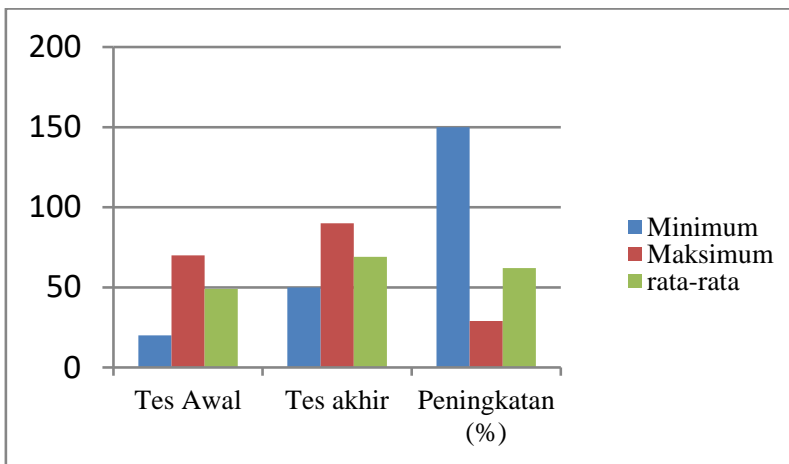

Gambar 2. Grafik nilai tes terendah, tertinggi, rata-rata, dan persentase peningkatan nilai tes peserta pelatihan

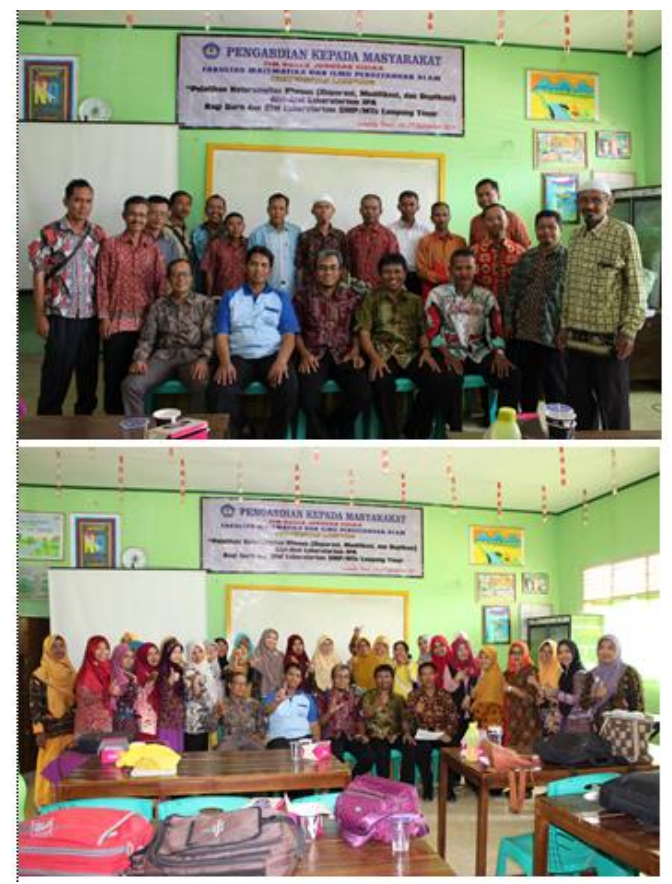

Gambar 3. Tim pelaksana dengan peserta pelatihan

\section{B. Faktor Pendukung Kegiatan}

Faktor pendukung kegiatan adalah dana yang diberikan LPPM Universitas Lampung, tempat penyelenggaraan di SMPN 1 Batanghari, dan Musyawarah Guru Mata Pelajaran (MGMP) IPA Lampung Timur yang telah membantu menginformasikan kepada guru IPA SMP/MTs di Kabupaten Lampung Timur.

\section{KESIMPULAN}

Terdapat peningkatan pengetahuan (kompetensi) dan keterampilan pengelolaan laboratorium bagi seluruh peserta setelah mengikuti pelatihan. Hal ini ditunjukkan dengan data peningkatan nilai hasil tes (tes awal dan tes akhir). Nilai tes awal terendah 20 , tertinggi 70 , dan ratarata 49. Sedangkan Hasil tes akhir diperoleh nilai terendah 50, tertinggi 90, dan rata-rata 69. Guru IPA SMP/MTs memerlukan pembinaan yang intensif agar kualitas layanan praktikum pembelajaran IPA dapat ditingkatkan kualitasnya. Di samping itu perlu diberikan pelatihan keterampilan khusus (reparasi, modifikasi dan duplikasi) alat-alat Laboratorium IPA secara 
berkala, agar guru IPA dapat mengembangkan dan memodifikasi peralatan praktium di sekolah.

Berdasarkan hasil kegiatan dan tanggapan peserta selama kegiatan, perlu adanya perhatian nyata dari pemerintah (Dinas Pendidikan) untuk melakukan kegiatan sejenis pada mata pelajaran lain untuk meningkatkan pengetahuan guru dalam melaksanakan tugasnya. Alokasi dana dari pemerintah diperlukan untuk melengkapi perlalatan labotaorium di seluruh SMP agar pelaksanaan pembelajaran berpraktikum dapat dilaksanakan dengan baik.

\section{UCAPAN TERIMAKASIH}

Ucapan terimakasih kami sampaikan kepada semua pihak yang telah membantu terlaksananya kegiatan ini, yaitu: Universitas Lampung melalui Lembaga Penelitian dan Pengabdian Kepada Masyaraakat (LPPM) Unila Tahun Anggaran 2019 dan Kepala Sekolah SMPN 1 Batanghari, atas bantuannya dalam menyediakan fasilitas dan tempat pelaksanaan kegiatan.

\section{REFERENSI}

Dirjen Dikdasmen Kemendikbud. (2017).

Panduan Pengelolaan dan Pemanfaatan

Laboratorium IPA

Habibi. (2012). Pembelajaran IPA 1 (edisi revisi). Sumenep : Unija Press.

Hofstein, A dan R.M. Naaman. (2007). The laboratory in science education: the state of the art. Journal the Royal Society of Chemistry, 8(2), 105107.
Ismawati , Riva dan Eli Trisnowati. (2019). Pelatihan Pengelolaan Laboratorium IPA Bagi Guru SMP/MTs Kecamatan Windusari. J-ABDIPAMAS (Jurnal Pengabdian Kepada Masyarakat). 3(1): $67-73$

Subamia, IDP. (2012). Pelatihan Keterampilan Dasar Laboratorium (Basic Laboratory Skill) Bagi Staf Laboratorium IPA SMP Se-Kabupaten Buleleng. Widya Laksana. 1(2): $36-48$.

Sutrisno, E. (2010) Manajemen Sumber Daya Manusia, Cetakan Kelima. Yogyakarta: Prenada Media

Utami, Rizka Rida, Edy Cahyono , dan Kasmadi Imam Supardi. (2017). Pengembangan Kit Hukum-Hukum Dasar Kimia untuk Meningkatkan Pencapaian Kompetensi Siswa melalui Pendekatan Ilmiah. Journal of Innovative Science Education. 6(1): $28-39$.

Yani, Ahmad, Sidin Ali, dan Mutahharah Hasyim. (2019) Pelatihan keterampilan memperbaiki alat ukur di laboratorium pada Kelompok MGMP Fisika di Kota Parepare. Prosiding Seminar Nasional Lembaga Penelitian dan Pengabdian Kepada Masyarakat Universitas Negeri Makassar . ISBN: 978-623-7496-01-4: $608-610$.

Yuliana, Yusminah Hala, dan A. Mushawwir Taiyeb (2017) Efektifitas Penggunaan Laboratorium Terhadap Motivasi dan Hasil Belajar IPA Peserta Didik SMPN 3 Palakka Kabupaten Bone. Jurnal Nalar Pendidikan. 5(1): 39-45 